\title{
Analisa Performa Pada Cooling Tower Jenis Mechanical Draft Crossflow
}

\author{
Alvera Apridalianti Melkias ${ }^{1}$ \\ ${ }^{1}$ Jurusan Teknik Konversi Energi, Politeknik Negeri Bandung \\ email : alveramelkias@polban.ac.id
}

\begin{abstract}
Abstrak
Sistem pendingin pada unit PLTP terdiri dari dua macam sistem sirkulasi yaitu sistem air pendingin utama ( Main Cooling Water System ) yang melayani pendinginan pada kondensor dan sistem air pendingin sekunder ( Secondary Cooling Water System ) yang melayani pendinginan untuk peralatan bantu. Jenis cooling tower yang dipergunakan pada unit PLTP Kamojang adalah mechanical draft crossflow tower. Tujuan penelitian ini yaitu untuk menganalisis menara pendingin di Pembangkit Listrik Tenaga Panas Bumi Kamojang. Untuk mengetahui kinerja Cooling Tower pada saat dioperasikan, analisis kalor yang terevaporasi, kalor pendinginan dari air ke cooling tower serta nilai efektivitas Cooling Tower. Metode analisis yang digunakan adalah membandingkan nilai kalor evaporasi, kalor pendingin serta nilai efektivitas berdasarkan data desain dan data operasi pada sistem. Berdasarkan hasil perhitungan serta analisa yang telah dilakukan maka diperoleh kesimpulan bahwa kalor evaporasi pada data desain yaitu 242,437.76 $\mathrm{kW}$ dan kalor pendinginan 242,027.93 $\mathrm{kW}$ sedangkan pada data operasi kalor evaporasi sebesar $298,496.06 \mathrm{~kW}$ dan kalor pendinginan 298,374.40 kW. Nilai efektivitas pada data desain sebesar $64 \%$ sedangkan pada data operasi sebesar 59,37\% adanya penurunan sebesar 4,63\%.
\end{abstract}

Kata Kunci: cooling tower, kalor evaporasi, kalor pendinginan, efektivitas.

\section{PENDAHULUAN}

\section{I.1 Latar Belakang}

Cooling tower merupakan suatu sistem refrigerasi yang melepaskan kalor ke udara.cooling tower bekerja dengan cara mengontakkan air dengan udara dan menguapkan sebagian air tersebut.

Cooling tower yang dipergunakan pada unit PLTP Kamojang adalah mechanical draft crossflow tower, udara masuk melalui sisi kisi menara yang cukup besar dan bergerak melalui fill. Fan blade dipasang dipuncak menara, dan dari puncak menara tersebut dibuang udara panas dan lembab ke udara bebas. Nilai kalor evaporasi serta kalor pendinginan dari air ke cooling tower seharusnya menghasilkan nilai yang sama atau tidak jauh berbeda, maka perlu dilakukan analisis berdasarkan data desain dan data operasi yang ada pada sistem, serta analisis pada efektivitas cooling tower.

\section{I.2 Tujuan Penelitian}

Tujuan penelitian ini yaitu untuk menganalisis menara pendingin di Pembangkit Listrik Tenaga Panas Bumi Kamojang. Untuk mengetahui kinerja Cooling Tower pada saat dioperasikan.
1. Analisis kalor evaporasi dan kalor pendinginan pada cooling tower.

2. Analisis nilai efektivitas cooling tower.

\section{I.3 Rumusan Masalah}

Kalor evaporasi, kalor pendinginan serta efektivitas pada cooling tower sangat penting untuk mempercepat proses pendinginan air, sehingga analisis yang dilakukan diharapkan mampu memberikan hasil yang baik pada sistem.

\section{I.4 Batasan Masalah}

Adapun batasan masalah adalah sebagai berikut :

1. Cooling tower yang diteliti berada di PLTP Kamojang.

Analisis yang dilakukan meliputi kalor evaporasi, kalor pendinginan, serta nilai efektivitas cooling tower.

\section{TINJAUAN PUSTAKA}

Panas dapat diekstraksi dari air pendingin menggunakan penukar panas berpendingin udara, yang dapat beroperasi baik dalam rancangan paksa atau konsep alami, yang terakhir sering disebut sebagai "menara pendingin kering". Namun, sistem yang lebih 
umum adalah sistem yang melibatkan perpindahan panas kontak langsung antara air pendingin dan udara. Dalam menara pendingin "basah" seperti itu, panas ditolak sebagian oleh perpindahan panas "masuk akal" antara air dan udara dan sebagian oleh perpindahan panas evaporatif, yang dihasilkan dari penguapan sebagian air dan udara yang mengalir ke bawah menara , ini meningkatkan kelembaban udara.

\subsection{Induced draft cross flow}

Udara mengalir kemasan dalam aliran lintas ke air yang mengalir ke bawah itu. Desain ini memiliki keunggulan ketinggian rendah, yang mungkin diinginkan dari sudut pandang lingkungan. Kerugiannya adalah pengurangan efisiensi karena penggunaan aliran silang alih-alih aliran arus balik, dan ada juga masalah dalam mengamankan distribusi air yang baik di atas kemasan untuk pola aliran yang kompleks.

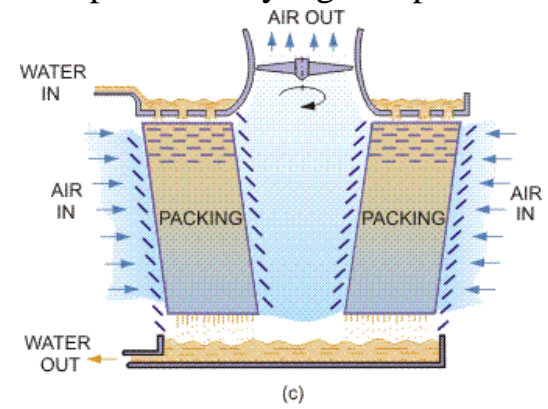

Gambar 1. Induced draft cross flow

\subsection{Range}

Range adalah perbedaan antara suhu air masuk dan keluar cooling tower. Range cooling tower yang tinggi menunjukan bahwa menara pendingin telah mampu menurunkan suhu air secara efektif, dan kinerjanya bagus.

Range $\mathbf{C T}\left({ }^{\circ} \mathrm{C}\right)=\left[\right.$ temperatur masuk $\mathrm{CW}\left({ }^{\circ} \mathrm{C}\right)-$ temperatur keluar $\left.\mathrm{CW}\left({ }^{\circ} \mathrm{C}\right)\right]$

\subsection{Approach}

Approach adalah perbedaan suhu air dingin keluar cooling tower dan suhu wet bulb ambient. Saat kondisiapproach rendah maka semakin baik performa menara pendingin. Range dan approach tetap dipantau, 'approach' adalah indikator yang lebih baik untuk kinerja cooling tower.

Approach CT $\left({ }^{\circ} \mathrm{C}\right)=\left[\right.$ temperatur keluar $\mathrm{CW}\left({ }^{\circ} \mathrm{C}\right)-$ temperatur wet bulb $\left.\left({ }^{\circ} \mathrm{C}\right)\right]$

\subsection{Efektivitas}

Efektivitas adalah perbandingan dalam persentase antara range dan range ideal ialah perbedaan antarasuhu air pendingin masuk dan suhu wet bulb ambien, atau dengan rumus $=$ Range $($ Range + Approach). Semakintinggi dalam perbandingan ini, akan semakin tinggi pula efektivitas cooling tower.

Efektivitas CT $(\%)=\frac{\text { Range }}{(\text { Range }+ \text { Approach })} \times 100 \%$

\section{METODOLOGI PENELITIAN}

Sistem pendingin pada unit PLTP terdiri dari dua macam sistem sirkulasi yaitu sistem air pendingin utama ( Main Cooling Water System ) yang melayani pendinginan pada kondensor dan sistem air pendingin sekunder ( Secondary Cooling Water System ), yang melayani pendinginan untuk peralatan bantu seperti Oil Cooler, Generator Air Cooler, dan Compressor Air Cooler.

Pendinginan ini terjadi sebagai akibat adanya penguapan dari sebagian air kedalam aliran udara yang mempunyai kelembaban rendah, sehingga air panas akan melepaskan sebagian panas sensibelnya dengan jumlah yang sama dengan jumlah panas laten yang diperlukan untuk terjadinya penguapan tersebut.

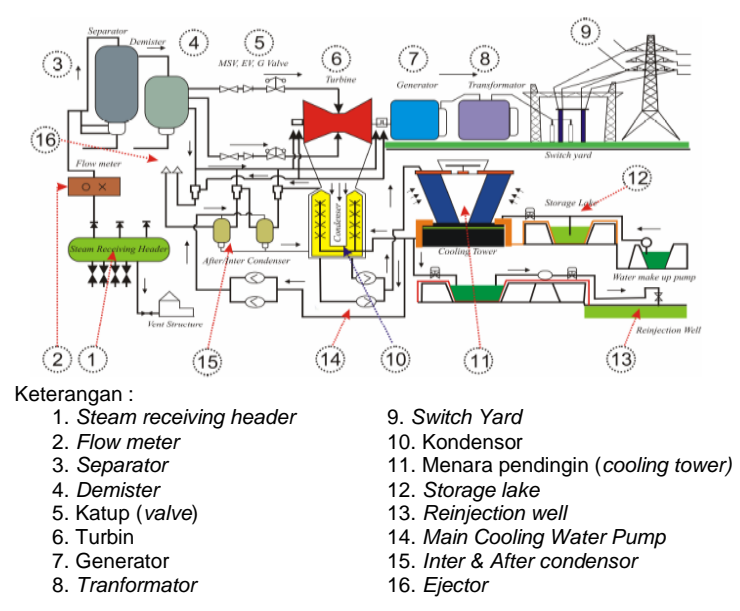

Gambar 2. Diagram Alir PLTP Kamojang

Jenis cooling tower yang dipergunakan pada unit PLTP Kamojang adalah mechanical draft crossflow tower dengan material utama konstruksinya adalah kayu yang telah diawetkan, selain kayu material lain biasanya berupa beton. Pada jenis ini udara masuk melalui sisi kisi menara yang cukup besar dan bergerak melalui fill. Fan blade dipasang dipuncak menara, dan dari puncak 
menara tersebut dibuang udara panas dan lembab ke udara bebas. Cooling tower pada PLTP mempunyai 5 sel dan 8 fan blade. Bak air panas ( hot water basin) yang berada diatas menara menampung dan mendistribusikan air panas yang keluar dari kondensor dengan memancarkan air tersebut dengan nozel-nozel pemancar secara grafitasi. Air ini jatuh dan kontak langsung dengan udara pendingin melalui isian ( fill) selanjutnya dikumpulkan di bak air pendingin ( cool water basin ).

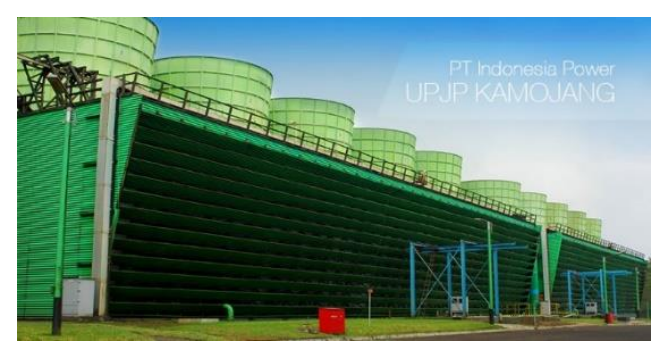

Gambar 3. Cooling Tower PLTP Kamojang

Konstruksi dari menara pendingin terdiri dari :

Fan yang berfungsi untuk menarik udara dingin dan mengedarkan udara di menara untuk mendinginkan air. Menara pendukung yang berfungsi untuk mendukung menara dingin untuk berdiri teguh dan tegak.

Rumah menara pendingin (casing) yang memiliki ketahanan yang baik terhadap semua cuaca dan umur (life time) panjang.

> Pipa sprinkler adalah pipa yang berfungsi untuk mengedarkan air secara merata pada menara pendingin, sehingga transfer panas ke air menjadi efektif dan efisien. Pipa sprinkler dilengkapi dengan lubang kecil untuk menyalurkan air.

Reservoirs (water basin) sebagai pengumpulan sementara air yang jatuh dari mengisi bahan sebelum diedarkan kembali ke kondensor.

Inlet louver berfungsi sebagai pintu masuk udara melalui lubang lubang di sana. Melalui inlet louvers akan terlihat kualitas dan kuantitas air akan didistribusikan. Inlet louvers terbuat dari seng

Fillers yang berfungsi sebagai tempat bercampurnya air yang jatuh dengan udara bergerak ke atas.

Metodologi yang dijalankan dalam penelitian

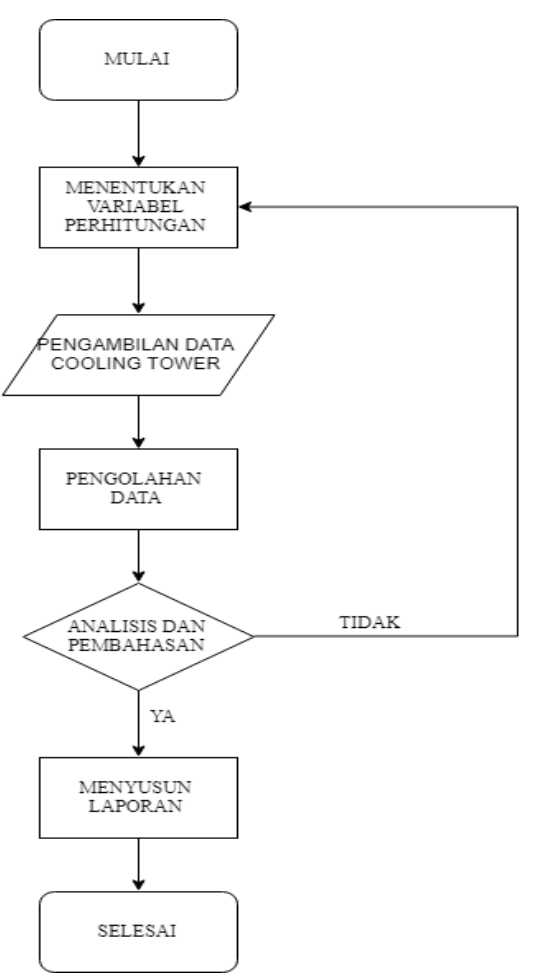

Gambar 4. Diagram Alir Metodologi Penelitian

\section{HASIL DAN PEMBAHASAN}

\subsection{Data Desain}

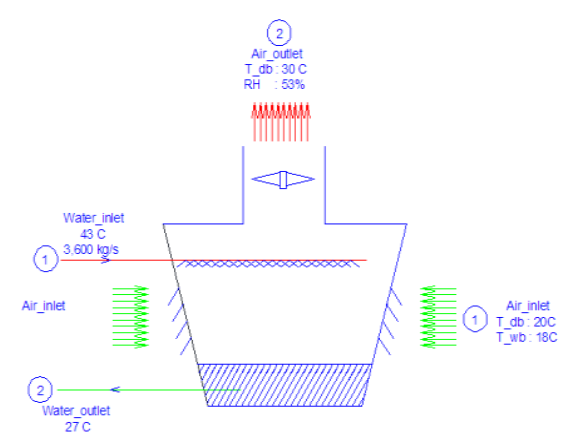

Air

$\begin{array}{llrl}\mathrm{T}_{\text {in }} & : & 43.00 & { }^{\circ} \mathrm{C} \\ \mathrm{T}_{\text {out }} & : & 27.00 & { }^{\circ} \mathrm{C} \\ \text { Flow_rat in } & : 12.960 .000 & \mathrm{~m}^{3} / \mathrm{hr} \\ & : 3.600 .000 & \mathrm{~kg} / \mathrm{s} \\ \text { Flow_rat_out } & : 12.420 & \mathrm{~m} / \mathrm{hr} \\ & : 3.450 & \mathrm{~kg} / \mathrm{s} \\ \mathrm{C}_{\mathrm{p}} & : 4.20 \quad \mathrm{~kJ} / \mathrm{kg} . \mathrm{K} \\ \mathrm{Q}_{\text {in }} & : \dot{m}_{\text {int }} x c_{p} x\left(T_{\text {int }}-T_{\text {out }}\right) \\ \mathrm{Q}_{\text {in }} & : 241,920.000 \quad \mathrm{~kW}\end{array}$

\section{Udara}

Udara_masuk

$\mathrm{T}_{\mathrm{db}} \quad: 20$

${ }^{\circ} \mathrm{C}$

$\mathrm{T}_{\mathrm{wb}} \quad: 18$

${ }^{\circ} \mathrm{C}$ 


$\begin{array}{lll}\mathrm{h}_{1} & : 51.00 & \mathrm{~kJ} / \mathrm{kg} \\ \Upsilon_{1} & : 0.012 & \mathrm{~kg} / \mathrm{kg} \text { d.a }\end{array}$

\section{Asumsi}

Udara_keluar

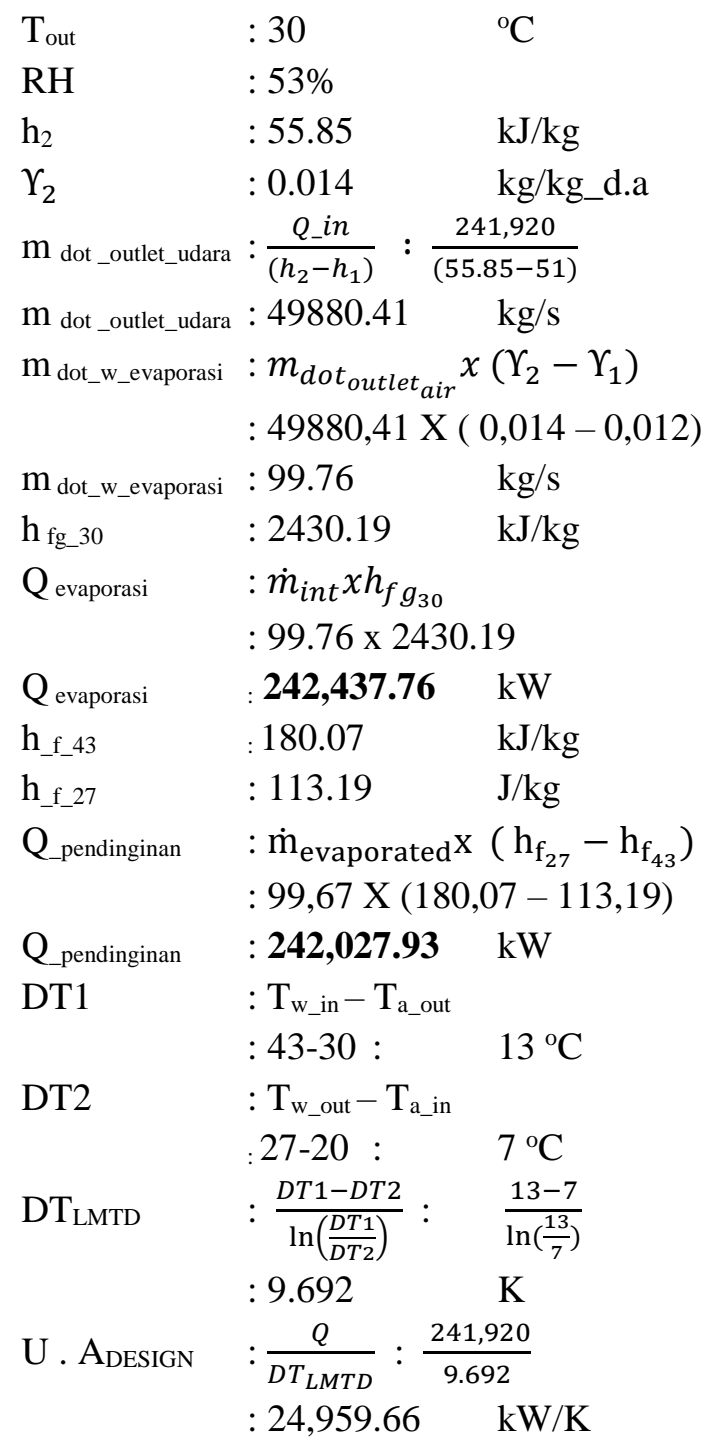

Range $\mathrm{CT}\left({ }^{\circ} \mathrm{C}\right)=\left[\right.$ temperatur masuk $\mathrm{CW}\left({ }^{\circ} \mathrm{C}\right)-$ temperatur keluar $\left.\mathrm{CW}\left({ }^{\circ} \mathrm{C}\right)\right]$

$$
\begin{aligned}
& =\left[43^{\circ} \mathrm{C}-27^{\circ} \mathrm{C}\right] \\
& =16^{\circ} \mathrm{C}
\end{aligned}
$$

Approach $\mathrm{CT}\left({ }^{\circ} \mathrm{C}\right)=$ temperatur keluar $\mathrm{CW}\left({ }^{\circ} \mathrm{C}\right)-$ temperatur wet bulb $\left.\left({ }^{\circ} \mathrm{C}\right)\right]$

$$
\begin{aligned}
& =\left[27^{\circ} \mathrm{C}-18^{\circ} \mathrm{C}\right] \\
& =9^{\circ} \mathrm{C}
\end{aligned}
$$

Efektivitas CT $(\%)=\frac{\text { Range }}{(\text { Range }+ \text { Approach })} \times 100 \%$

$$
\begin{aligned}
& =\frac{16^{\circ} \mathrm{C}}{\left(16^{\circ} \mathrm{C}+9^{\circ} \mathrm{C}\right)} \times 100 \% \\
& =\mathbf{6 4 \%} \%
\end{aligned}
$$

\subsection{Data Operasi}

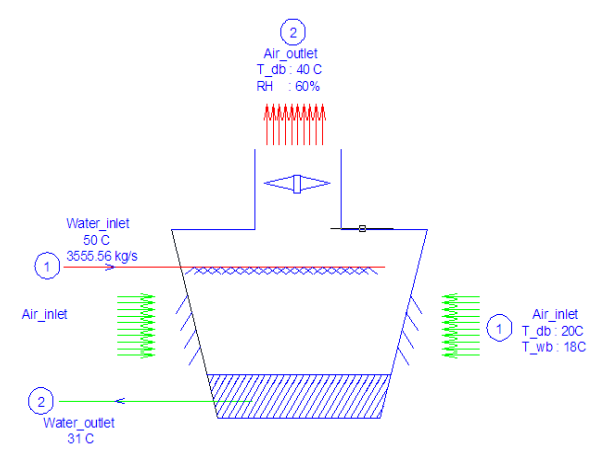

\section{Air}

$$
\begin{array}{lll}
\mathrm{T}_{\text {in }} & : 31 & { }^{\circ} \mathrm{C} \\
\mathrm{T}_{\text {out }} & : 50 & { }^{\circ} \mathrm{C} \\
\dot{m}_{\text {out }} & : 12,800 & \text { ton } / \mathrm{hr} \\
& : 3,555 & \mathrm{~kg} / \mathrm{s} \\
\mathrm{Cp} & : 4.2 & \mathrm{~kJ} / \mathrm{kg} . \mathrm{K} \\
\mathrm{Q} & : \dot{m} x c_{p} x\left(T_{\text {int }}-T_{\text {out }}\right) \\
& : 3,555.56 \times 4.2 \times(50-31) \\
\mathrm{Q}_{\text {hot out }} & : 283,733.33 \quad \mathrm{~kW}
\end{array}
$$

\section{Udara}

Udara_inlet

$\begin{array}{lll}\mathrm{T}_{\_} \mathrm{db} & : 20.00 & { }^{\circ} \mathrm{C} \\ \mathrm{T}_{\_} \mathrm{wb} & : 18.00 & { }^{\circ} \mathrm{C} \\ \mathrm{h}_{1} & : 51.00 & \mathrm{~kJ} / \mathrm{kg} \\ \mathrm{\Upsilon}_{1} & : 0.012 & \mathrm{~kg} / \mathrm{kg} \_\mathrm{d} . \mathrm{a}\end{array}$

\section{Asumsi}

\section{Udara_keluar}

$\begin{array}{lll}\mathrm{T}_{\text {_out }} & : 40 & { }^{\circ} \mathrm{C} \\ \mathrm{RH} & : 60 \% & \\ \mathrm{~h}_{2} & : 74.1 & \mathrm{~kJ} / \mathrm{kg} \\ \mathrm{\Upsilon}_{2} & : 0.022 & \mathrm{~kg} / \mathrm{kg} \text { d.a }\end{array}$

m_dot_outlet_udara $: \frac{Q \_ \text {outlet }}{\left(h_{2}-h_{1}\right)}=\frac{283,733.33}{(74.1-51)}$

m_dot_outlet_udara : $12,282.83 \quad \mathrm{~kg} / \mathrm{s}$

$\mathrm{m}_{- \text {dot_w_evaporasi }:}: m_{\text {dot }_{\text {outlet }} \text { air }} x\left(\Upsilon_{2}-\Upsilon_{1}\right)$ : $12,282 \times(0,022-0,012)$

m_dot_w_evaporasi $: 122.83 \quad \mathrm{~kg} / \mathrm{s}$

$\mathrm{h}_{\text {fg__30 }} \quad: 2430.19 \quad \mathrm{~kJ} / \mathrm{kg}$

Q_evaporasi : m_dot_w_evaporated $\mathrm{X}$ h_(fg_30) : $122.83 \times 2430.19$

Q_evaporasi : 298,496.06 $\mathrm{kW}$

$\mathrm{h}_{-} \mathrm{f}_{5} 50 \quad: 209.34 \quad \mathrm{~kJ} / \mathrm{kg}$

$\mathrm{h}_{-} \mathrm{f}_{3} 31 \quad: 129.91 \quad \mathrm{~kJ} / \mathrm{kg}$

Q_pendinginan $: \dot{m}_{\text {evaporated }} x\left(h_{f_{31}}-h_{f g_{50}}\right)$ 


$$
: 122,83 \times(209,34-129.91)
$$

$\mathrm{Q}_{\text {pendinginanr }}: \mathbf{2 9 8 , 3 7 4 . 4 0} \quad \mathrm{kW}$

DT1 : $\mathrm{T}_{\mathrm{w} \_ \text {in }}-\mathrm{T}_{\text {a_out }}$

$$
: 50-40 \quad: \quad 10 \mathrm{C}
$$

DT2 : $\mathrm{T}_{\mathrm{w} \_ \text {out }}-\mathrm{T}_{\mathrm{a} \_ \text {in }}$

$$
\text { :31-20 : } \quad 11 \mathrm{C}
$$

$\mathrm{DT}_{\mathrm{LMTD}}: \frac{D T 1-D T 2}{\ln \left(\frac{D T 1}{D T 2}\right)}: \quad \frac{10-11}{\ln \left(\frac{10}{11}\right)}$

$$
10.492 \quad \mathrm{~K}
$$

U.A.PERASI $: \frac{Q}{D T_{L M T D}}: \frac{283,733.33}{10.492}$

$$
\text { : } 27,042.68 \quad \mathrm{~kW} / \mathrm{K}
$$

Range $\mathrm{CT}\left({ }^{\circ} \mathrm{C}\right)=$ temperatur masuk $\mathrm{CW}\left({ }^{\circ} \mathrm{C}\right)-$ temperatur keluar $\left.\mathrm{CW}\left({ }^{\circ} \mathrm{C}\right)\right]$

$$
\begin{aligned}
& =\left[50^{\circ} \mathrm{C}-31^{\circ} \mathrm{C}\right] \\
& =19^{\circ} \mathrm{C}
\end{aligned}
$$

Approach $\mathrm{CT}\left({ }^{\circ} \mathrm{C}\right)=\left[\right.$ temperatur keluar $\mathrm{CW}\left({ }^{\circ} \mathrm{C}\right)-$ temperatur wet bulb $\left.\left({ }^{\circ} \mathrm{C}\right)\right]$

$$
\begin{aligned}
& =\left[31^{\circ} \mathrm{C}-18^{\circ} \mathrm{C}\right] \\
& =13^{\circ} \mathrm{C}
\end{aligned}
$$

Efektivitas CT $(\%)=\frac{\text { Range }}{(\text { Range }+ \text { Approach })} \times 100 \%$

$$
\begin{aligned}
& =\frac{19^{\circ} \mathrm{C}}{\left(19^{\circ} \mathrm{C}+13^{\circ} \mathrm{C}\right)} \times 100 \% \\
& =\mathbf{5 9 , 3 7 \%}
\end{aligned}
$$

\section{KESIMPULAN DAN SARAN \\ 5.1 Kesimpulan}

Berdasarkan hasil perhitungan serta analisa yang telah dilakukan maka diperoleh kesimpulan bahwa :
1. Kalor evaporasi pada data desain yaitu $242,437.76$ $\mathrm{kW}$ dan kalor pendinginan 242,027.93 kW sedangkan pada data operasi kalor evaporasi sebesar 298,496.06 $\mathrm{kW}$ dan kalor pendinginan $298,374.40 \mathrm{~kW}$.

2. Nilai efektivitas pada data desain sebesar $64 \%$ sedangkan pada data operasi sebesar 59,37\% adanya penurunan sebesar $4,63 \%$.

\subsection{Saran}

Pemeliharaan cooling tower secara preventif agar nilai efektivitas tetap baik. Perawatan operasional sistem secara berkala untuk water treatment program, pengolahan air blow down serta mengurangi tingkat kerusakan akibat pencemaran udara dan rusaknya atmosfer yang berasal dari pembuangan kalor.

\section{DAFTAR PUSTAKA}

[1] Muhsin,Ahmad., Pratama Zicko. Analisis Efektivitas Mesin Cooling Tower Menggunakan Range and Approach. Jurnal OPSI Vol II No.2 Desember 2018

[2] El Wakil, M.M., (1984), Powerplant Technology, McGraw Hill International, Singapore

[3] Fauzi, Danial Ahmad., Rudiyanto, Bayu. Analisa Performa Menara Pendingin Pada PT Geo Dipa Energi Unit Dieng. Jurnal Ilmiah Rotari, Vol 1 Agustus 2016. [4[ Handoyo, Yoppy. Analisis Perfoma Cooling Tiwer LCT 400 pada PT XYZ Tambun Bekasi. Jurnal Ilmiah Teknik Mesin, Vol.3 Februari 2015

[5] Hewitt, G.F. G.L Shires. T.R. Bott. 2000. Process Heat Transfer. United States of America : Begell House, Inc. 